\title{
The effect of hip joint exercise using an elastic band on dynamic balance, agility and flexibility in healthy subjects: a randomized controlled trial
}

\author{
Dong Hyun Kang, Woo Hyung Lee, Song Lim, Yu Yeong Kim, Soung Wook An, Chang Gyeong Kwon, \\ Gyeong Hee Lee, Nu Ri Choi, Na Yeong Lee, Bo Min Kim, Jae Hyeon Kim, Eun Jung Chung
}

Department of Physical Therapy, Andong Science College, Andong, Republic of Korea

\begin{abstract}
Objective: The purpose of this study was to examine the effects of hip joint exercise using an elastic band on dynamic balance, agility, and flexibility in healthy subjects.

Design: Randomized controlled trial.

Methods: Thirty-five subjects (between 19 and 23 years) were randomly allocated to two groups: hip flexion exercise (HFE) group $(n=17)$ and the hip abduction exercise (HAE) group $(n=18)$. The HFE group participated in flexion exercise of the hip joint using an elastic band for 50 minutes a day, three days a week for four weeks, while the HAE group participated in abduction exercises of the hip joint using an elastic band for the same period. Dynamic balance was measured using the timed up and go (TUG) test, agility was measured with the standing long jump, and flexibility was measured using the Schober's test $(5 \mathrm{~cm}, 10 \mathrm{~cm})$.

Results: The HFE group showed significant differences in the TUG test, standing long jump, and the Schober's test (10 cm) after training $(p<0.05)$. The HAE group showed significant differences in the TUG test, standing long jump and the Schober's test $(5$ $\mathrm{cm}, 10 \mathrm{~cm})$ after training $(p<0.05)$. However, there was no significant difference between the HFE group and the HAE group. Conclusions: Flexion and abduction exercises of the hip joint using and elastic band increased dynamic balance, agility, and flexibility in healthy subjects. Additional research on hip joint exercises using an elastic band for improving dynamic balance, agility and flexibility are necessary.
\end{abstract}

Key Words: Dynamic balance, Elastic band, Hip joint exercise

\section{Introduction}

The hip joint is an essential joint for pelvic alignment in the horizontal plane, regulation of trunk rotation and spinal functions. Therefore, alteration of pelvic movement could be induced from hip muscle weakness [1]. Additionally, loss of hip joint stability could result in issues with muscle function, which is crucial for activities of daily living (ADL) and purposeful activities [2]. Hip joint muscles play a role in providing trunk stabilization during the stance phase and control of the lower extremities during the swing phase. Therefore, hip joint muscle weakness may be the main cause of gait abnormality. ADL activities such as standing for long period of time, gait, sitting, and standing are limited and pain is induced from hip joint muscle weakness [3]. Salbach et al. [4] reported that lower extremity strength improvement from a gait enhancement program was effective for balance, velocity. Ferreira et al. [5] stated that the hip joint is a key factor for not only dynamic and static balance but also an important factor for weight loading. Therefore dysfunction of the hip joint has a negative impact on the distribution of weight.

Isokinetic exercises, bridging exercises, sling exercises, squats, and elastic band exercise are used to enhance the hip

Received: 21 November, 2016 Revised: 12 December, 2016 Accepted: 16 December, 2016

Corresponding author: Eun Jung Chung

Department of Physical Therapy, Andong Science College, 189 Seoseon-gil, Seohu-myeon, Andong 36616, Republic of Korea

Tel: 82-54-851-3752 Fax: 82-54-851-3559 E-mail: eunjung1984@hotmail.co.kr

(c) This is an Open-Access article distributed under the terms of the Creative Commons Attribution Non-Commercial License (http://creativecommons.org/licens es/by-nc/4.0) which permits unrestricted non-commercial use, distribution, and reproduction in any medium, provided the original work is properly cited.

Copyright @ 2016 Korean Academy of Physical Therapy Rehabilitation Science 
muscles [6], and among these exercises, the elastic band is capable of exercise level adjustments. If the elasticity of the band is slowly increased and the band is applied to a proper location, it may be considered as an appropriate strengthening exercise. Thus, the muscles and joints are not overloaded by this exercise. The increase in flexibility, strength, endurance as a result of an increase of ROM is constantly reported in many types of research, and since exercises with an elastic band are relatively affordable compared to machine resistant programs, portable, simple, and used for multiple purposes, they are currently commonly applied in the rehabilitation program [7]. These properties of elastic bands may be more effective to ADL performance (multi-directional movement), which does not occur in a single plane since resistance is appropriately applied to movements occurring in many biomechanical movement directions. Nowadays resistance exercise using an elastic band is commonly applied in strength training, sport rehabilitation, and disability rehabilitation, and is reported that 8 weeks of elastic band exercise increased muscle strength up to $14 \%-26 \%$ [8] In the advanced research, it is reported that not only strength, balance, proprioception, and function are improved but it also has preventative effects on chronic pain and damage [9]. However, there are several advanced research about elastic bands, and the studies do not compare flexion and abduction hip joint exercises using an elastic band.

Therefore, the purpose of this study was to examine the effect of hip joint exercises using an elastic band on dynamic balance, agility, and flexibility in healthy subjects. We hypothesized that hip joint exercises using elastic band would result in significant improvement of dynamic balance, agility, and flexibility.

\section{Methods}

\section{Subjects}

Thirty-five healthy subjects participated in this study.
Subjects were randomized into two groups, hip flexion exercise (HFE) group, and hip abduction exercise (HAE) group. The inclusion criteria was healthy, physically active volunteers between the ages 19 and 23 years, with no history of osteomyoarticular lesions or previous fracture or surgery to the hip joint, free of cardiovascular disease or neurological injury at the time of the experiment, non- corrected vestibular, visual and/or hearing impairments, in addition to displaying no allergy to adhesive material $[10,11]$.

Each member of the HFE group participated in hip flexion exercises using an elastic band for 50 minutes a day, three days a week for four weeks, while the HFA group participated in hip abduction exercises using an elastic band for the same period.

General characteristics of the subjects are shown in Table 1. There were 10 males and 7 females in the HFE group and 11 males and 7 females in the HAE group. The average age was 21.59 years in the HFE group and 21.00 years in the HAE group. The average height was $168.24 \mathrm{~cm}$ in the HFE group and $170.48 \mathrm{~cm}$ in the HAE group, and the average weight was $67.82 \mathrm{~kg}$ in the HFE group and $63.67 \mathrm{~kg}$ in the HAE group. This study was approved by the Sahmyook University's institutional review board (2-1040781-AB-N01-2016048HR). All subjects signed a written informed consent prior to participation.

\section{Procedures}

The HFE group participated in flexion exercises of the hip joint using an elastic band for three days a week for four weeks. The exercise program time was 50 minutes total with five minutes of stretching (warming up), 15-minutes of exercise, and an additional five minutes of stretching (cool down) in the supine position (25 minutes) (Figure 1) and standing position (25 minutes) (Figure 2), respectively (Table 2).

The HAE group participated in hip joint abduction exercises using an elastic band for three days a week for four weeks. The exercise program time was 50 minutes in total

Table 1. General characteristics of the subjects

\begin{tabular}{lccrc}
\hline \multicolumn{1}{c}{ Variable } & HFE group $(\mathrm{n}=17)$ & HAE group $(\mathrm{n}=18)$ & t/ $\chi^{2}$ & $p$ \\
\hline Sex (male/female) & $10 / 7$ & $11 / 7$ & 0.019 & 1.000 \\
Age (y) & $21.59(1.54)$ & $21.00(1.37)$ & 1.193 & 0.241 \\
Height (cm) & $168.24(8.24)$ & $170.48(10.40)$ & -0.704 & 0.486 \\
Weight (kg) & $67.82(15.41)$ & $63.67(11.70)$ & 0.902 & 0.374 \\
\hline
\end{tabular}

Values are presented as number only or mean (SD).

HFE: hip flexion exercise, HAE: hip abduction exericse. 


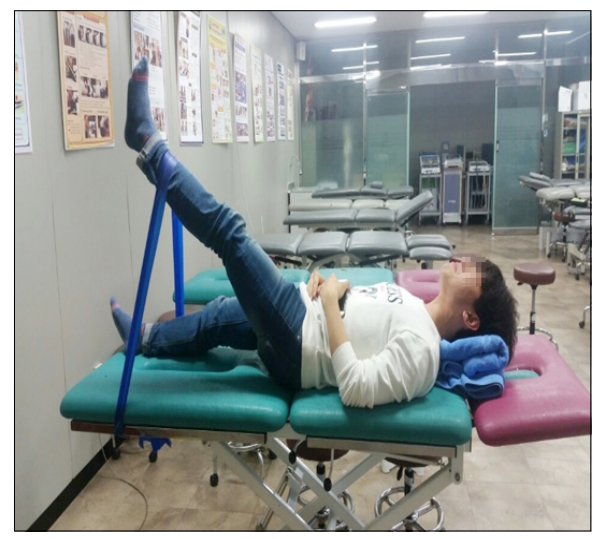

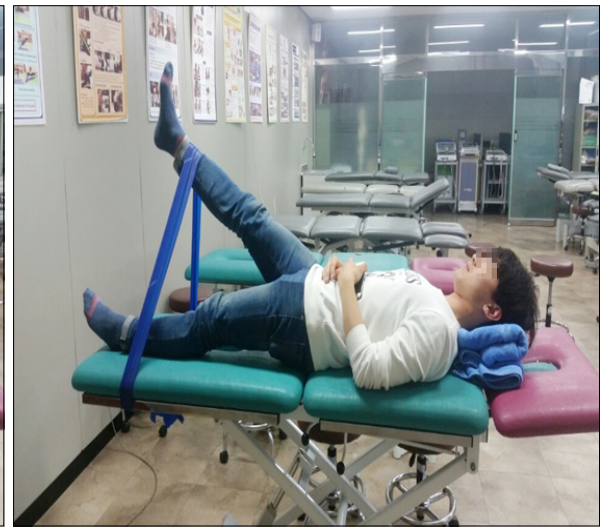

Figure 1. Flexion exercise in supine position.
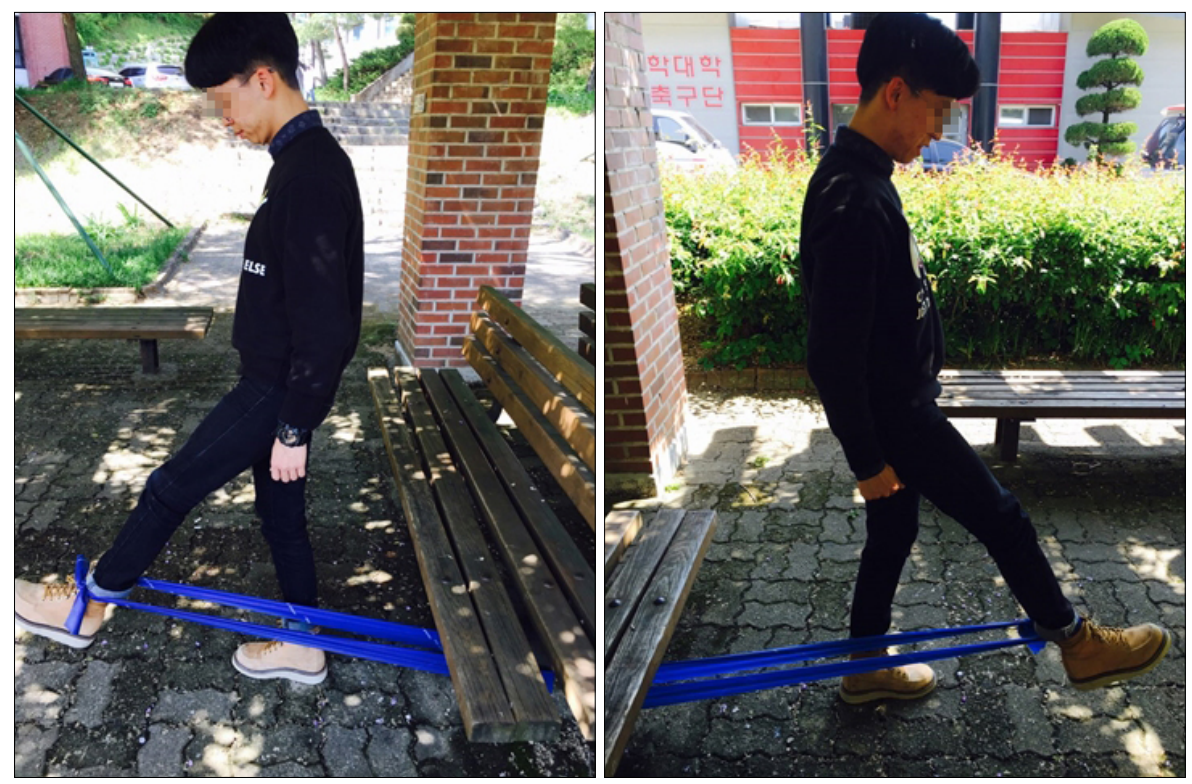

Figure 2. Flexion exercise in standing position.
Table 2. Flexion exercise of hip joint using elastic band (supine position and standing position, respectively)

\begin{tabular}{ll}
\hline Warming up & \multicolumn{1}{c}{ 5-minute set stretching } \\
\hline 1 set & Rt side hip joint flexion exercise (2 min) \\
& Lt side hip joint flexion exercise (2 min) \\
& 1-minute break \\
2 set & Rt side hip joint flexion exercise (2 min) \\
& Lt side hip joint flexion exercise (2 min) \\
& 1-minute break \\
& Rt side hip joint flexion exercise (2 min) \\
& Lt side hip joint flexion exercise (2 min) \\
& 1-minute break \\
Cool down & 5-minute set stretching \\
\hline
\end{tabular}

Rt: right, Lt: left. with five minutes of stretching (warming up), a 15-minutes of exercise, and an additional five 5 minutes of stretching (cool down) in the supine position (25 minutes) (Figure 3) and standing position (25 minutes) (Figure 4), respectively (Table 3).

All participants were trained according to their ability to adjust to the training intensity. One set of the elastic band exercise was composed of left side exercise for 2 minutes, right side exercise for 2 minutes and a 1-minute break (total $5 \mathrm{mi}$ nutes) in the supine position and standing position, respectively. Subjects conducted training 1 set of the three times, and started and stopped at the same time with command.

\section{Outcome measures}

In this study, dynamic balance was measured using the timed up and go (TUG) test, agility was measured using the 
standing long jump, and flexibility was measured using the Schober's test.

For the TUG test, subjects were seated in a chair with armrests and then instructed to stand (using the armrests, if desired) and walk as quickly and safely as possible for a distance of $3 \mathrm{~m}$. The subjects then turned around, returned to the chair, and sat down. The time from the point at which their spine left the back of the chair until they returned to that same position was recorded using a stopwatch $[12,13]$. High intra-rater (intraclass correlation coefficient $[\mathrm{ICC}]=0.99$ ) and inter-rater $(\mathrm{ICC}=0.99)$ reliability have been demonstrated using this measure [12].

For standing long jump measurement, a fiber-glass metric tape applied onto the floor was used. Subjects were in-

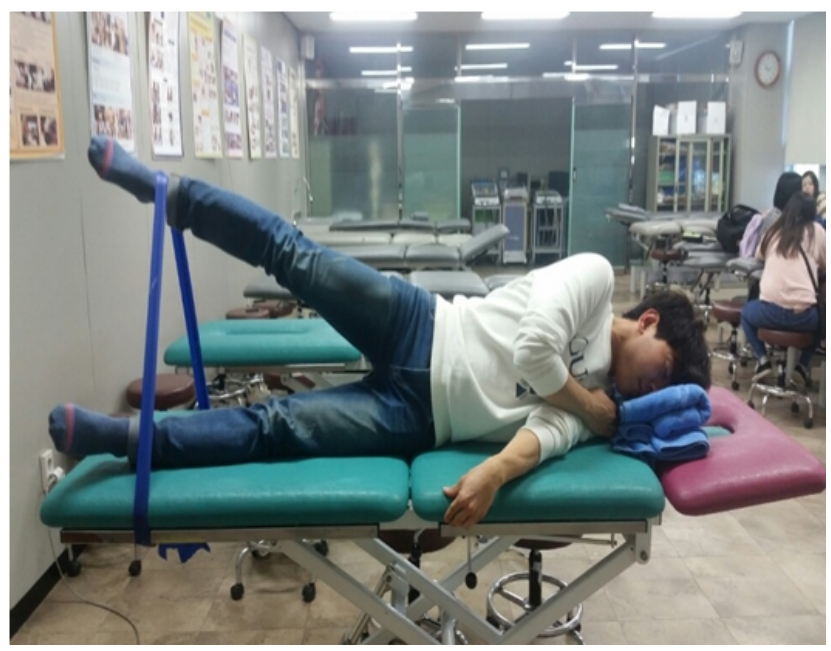

Figure 3. Abduction exercise in supine position. structed to use their arms to aid in the jump, positioning their feet shoulders-width apart and behind the zero point of the tape measure prior to jumping. Landing with the whole foot surface over the tape was measured between the zero point of the tape measure to the point at which the heel of the trial leg touched the ground. The highest jump distance of the three trials was used in subsequent analyses and expressed in centimeters $(\mathrm{cm})$ [14].

For the Schober's test, the examiner stood behind the subject and made three marks; one mark behind the lumbosacral junction; a second mark on a spinous process $10 \mathrm{~cm}$ above the first mark (measured to the nearest millimetre) and a third mark $5 \mathrm{~cm}$ below the first mark. The distance between the most inferior and superior marks were measured, with " 0 " at the inferior mark. Pressing the measuring tape against

Table 3. Abduction exercise of hip joint using elastic band (supine position and standing position, respectively)

\begin{tabular}{ll}
\hline Warming up & \multicolumn{1}{c}{ 5-minute set stretching } \\
\hline 1 set & Rt side hip joint abduction exercise $(2 \mathrm{~min})$ \\
& Lt side hip joint abduction exercise $(2 \mathrm{~min})$ \\
& 1-minute break \\
2 set & Rt side hip joint abduction exercise $(2 \mathrm{~min})$ \\
& Lt side hip joint abduction exercise $(2 \mathrm{~min})$ \\
& 1-minute break \\
3 set & Rt side hip joint abduction exercise $(2 \mathrm{~min})$ \\
& Lt side hip joint abduction exercise $(2 \mathrm{~min})$ \\
Cool down & 1-minute break \\
\hline
\end{tabular}

Rt: right, Lt: left.
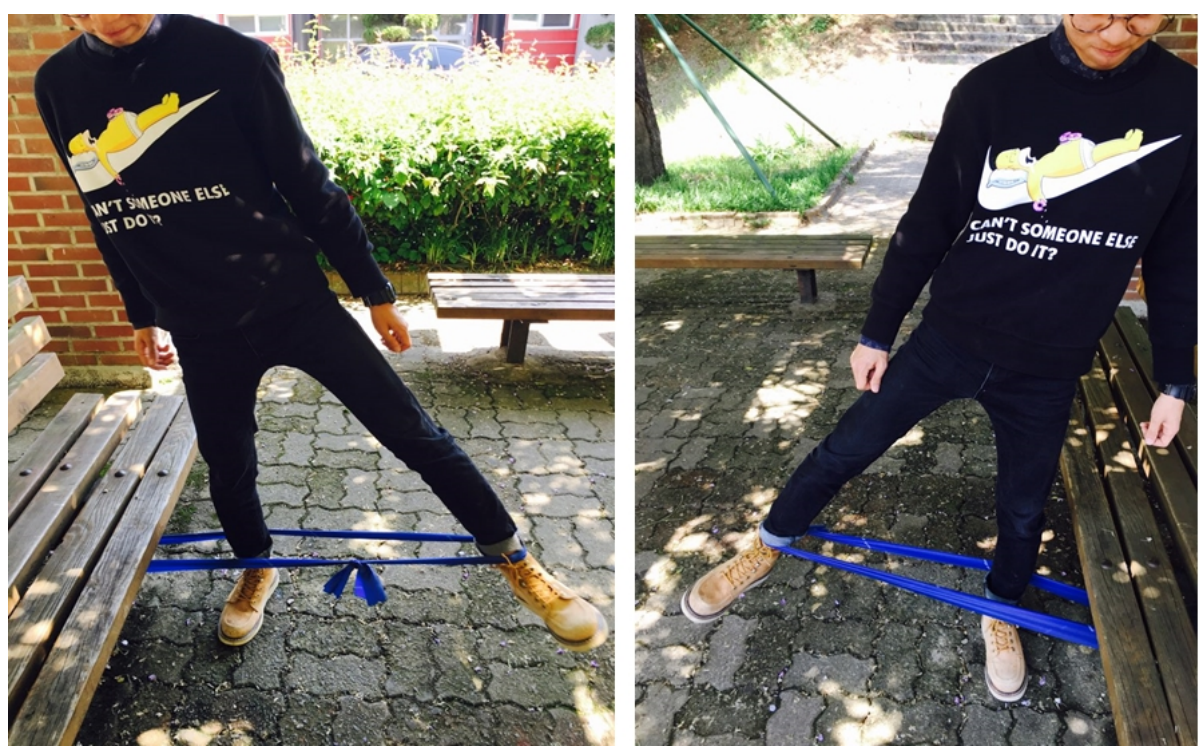

Figure 4. Abduction exercise in standing position. 
Table 4. Comparison of range of gait ability, agility, and flexibility within groups and between groups $(\mathrm{N}=35)$

\begin{tabular}{|c|c|c|c|}
\hline Variable & HFE group $(n=17)$ & HAE group $(n=18)$ & $\mathrm{t}(p)$ \\
\hline \multicolumn{4}{|c|}{ Timed up and go test (sec) } \\
\hline Pre & $7.18(0.85)$ & $6.68(0.73)$ & \multirow{4}{*}{$-1.094(0.282)$} \\
\hline Post & $5.73(0.98)$ & $5.55(0.59)$ & \\
\hline Change values & $1.45(0.87)$ & $1.14(0.81)$ & \\
\hline $\mathrm{t}(p)$ & $6.875(<0.001)$ & $5.943(<0.001)$ & \\
\hline \multicolumn{4}{|c|}{ Standing long jump (cm) } \\
\hline Pre & $187.91(41.55)$ & $185.97(35.38)$ & \multirow{4}{*}{$-0.592(0.558)$} \\
\hline Post & $201.61(37.88)$ & $202.39(32.90)$ & \\
\hline Change values & $-13.71(11.16)$ & $-16.42(15.44)$ & \\
\hline $\mathrm{t}(p)$ & $-5.065(<0.001)$ & $-4.512(<0.001)$ & \\
\hline \multicolumn{4}{|c|}{ Schober's test $(5 \mathrm{~cm})(\mathrm{cm})$} \\
\hline Pre & $6.13(0.44)$ & $16.53(2.97)$ & \multirow{4}{*}{$-0.360(0.721)$} \\
\hline Post & $6.36(0.31)$ & $17.00(3.16)$ & \\
\hline Change values & $-0.23(0.45)$ & $0.47(2.33)$ & \\
\hline $\mathrm{t}(p)$ & $-2.084(0.054)$ & $0.777(0.450)$ & \\
\hline \multicolumn{4}{|c|}{ Schober's test $(10 \mathrm{~cm})(\mathrm{cm})$} \\
\hline Pre & $35.00(6.27)$ & $38.13(5.99)$ & \multirow{4}{*}{$-1.483(0.147)$} \\
\hline Post & $40.33(5.81)$ & $40.00(6.27)$ & \\
\hline Change values & $5.33(7.90)$ & $1.87(4.07)$ & \\
\hline $\mathrm{t}(p)$ & $2.615(0.020)$ & $1.777(0.097)$ & \\
\hline
\end{tabular}

Values are presented as mean (SD).

HFE: hip flexion exercise, HAE: hip abduction exericse.

subject's lower back, subjects were instructed to bend forward keeping the knees straight, and the distance between the most superior and inferior marks at the end of the range of movement (ROM) was recorded. The ROM was assessed by measuring the difference in length from the beginning point (from the $15 \mathrm{~cm}$ mark) to the end of the range of motion point [15].

\section{Statistical analysis}

All statistical analyses were performed using PASW Statistics ver. 18.0 (IBM Co., Armonk, NY, USA). The general characteristics are presented as frequencies and percentages, with average and standard deviations also provided. The paired t-test was used for analysis of changes in independent variables before and after the training. The independent t-test was used for analysis of changes in dependent variables between groups. The significance threshold was set at $p<0.05$.

\section{Results}

Differences in dynamic balance, agility, and flexibility after the interventions are shown in Table 4. The flexion group showed significant differences in the TUG test, standing long jump and Schober's test $(10 \mathrm{~cm})$. The abduction group showed significant differences in the TUG test, standing long jump and Schober's test $(5 \mathrm{~cm}, 10 \mathrm{~cm})$. However, there was no significant difference between the flexion group and the abduction groups.

\section{Discussion}

The hip joint is a ball and socket joint with the second largest amount of range of motion [16]. As a representing muscle of the hip abductors, the gluteus medius produces hip abduction, provides regulation of the hip joint, and controls the pelvic lateral dynamic stabilization. Therefore, selective gluteus medius enhancement is essential for functional lower extremity movement [17]. The gluteus maximus is primarily a hip joint extensor and a lateral rotator, and the upper part of gluteus maximus is considered as a lateral rotator during gait. The lateral part of the hamstrings is primarily a hip joint extensor and secondly, it is a lateral rotator of the muscle [18]. Therefore, hip joint abductor and extensor muscle enhancement is essential to lumbar and pelvic stability [19].

An elastic band is a rubber band with elasticity and resistance, and the velocity and intensity of the resistance of an elastic band can be controlled. Elastic bands can be used in 
various ways just as exercise can be performed in all directions. Considering that exercises using elastic bands, are easy to carry, economical and safe, elastic bands can be used to improve muscular strength, flexibility, and balance control $[20,21]$.

Equilibrium is a state of no movement or a process of regulation of center of gravity (COG) during movement of the base of support (BOS), and Bobath [22] stated that consistent postural control and adaptation processes are necessary to maintain postures and COG in the BOS. In this study, TUG test was used to assess changes in dynamic balance ability before and after intervention.

Mangione et al. [23] reported that TUG tests were decreased after performing progressive resistant exercises using an elastic band of older adults. Park et al. [24] reported that strengthening exercise programs in the rural elderly population resulted in a decrease in TUG scores (from 9.8 to $9.0 \mathrm{sec}$ ). In this study, the TUG results showed significant differences in the HFE group (from 7.18 to $5.73 \mathrm{sec}$ ) and the abduction group (from 6.68 to $5.55 \mathrm{sec}, p<0.05$ ). However, there was no significant difference between the HFE and the HAE group. We speculate that equilibrium has a close relationship with strength and improvement of stability is a result of flexion and abduction muscle enhancement from elastic band exercise performance.

Agility is an ability related to the accuracy, quickness, and ease of being able to change in direction during exercise of either the partial or the entire body [25], and in this study, agility was measured with the standing long jump to assess changes in agility before and after intervention. Asadi and Ramírez-Campillo [14] compared the effects of a 6-week cluster versus traditional plyometric training set on standing long jump. As a result, both groups (cluster group: from 201.2 to $213.7 \mathrm{~cm}$, traditional group: from 192.0 to 204.7 $\mathrm{cm}$ ) showed significant differences in standing long jump $(p<0.05)$. In this study, there were significant differences in the standing long jump in the HFE group (from 187.91 to $201.61 \mathrm{~cm}$ ) and the HAE group (from 185.97 to $202.39 \mathrm{~cm}$, $p<0.05)$. However, there was no significant difference between the HFE and the HAE group. Through hip joint flexion and abduction exercises, lower extremity strength was increased with increased muscle contraction velocities compared to the pre-experimental state. Thus, more energy was produced in a shorter period of time and agility was considered to be increased.

Flexibility is an ability to move in the full range of motion. Since aging begins earlier than other physical ability ele- ments, and detraining starts rapidly, consistent training is needed. In this study, the Schober's test was used to assess changes in flexibility before and after intervention. Delshad et al. [26] reported that resistance training programs using Thera-Band tubing in elderly women during 12 weeks of intervention showed significant increases in trunk flexion (from 7.1 to $9.4 \mathrm{~cm}$ ) and after four weeks of detraining, there were significant decreases in trunk flexion (from 9.4 to 9.0 $\mathrm{cm})$. In this study, the Schober's test $5 \mathrm{~cm}$ showed no significant differences in the HFE group (from 6.13 to $6.36 \mathrm{~cm}$ ) but there were significant differences in the abduction group (from 6.16 to $6.45 \mathrm{~cm}, p<0.05$ ). However, there was no significant difference between the HFE group and the HAE group. Schober's test $10 \mathrm{~cm}$ showed significant differences in HFE group (from 14.86 to $15.23 \mathrm{~cm}$ ) and abduction group (from 14.70 to $15.45 \mathrm{~cm}, p<0.05$ ). However, there was no significant difference between the HFE group and the abduction group. The conduction of both flexion and abduction exercise increased flexibility. ROM increases due to hip joint flexion and abduction exercises results in less limitations in ADL performance and flexion and abduction itself, and therefore, it is considered that the exercise is effective on flexibility improvement. As a result, both flexion and abduction exercises using an elastic band were effective exercises for the hip joint because both flexion and abduction movement contribute to stabilization of hip joint.

There were several limitations to this study. First, due to a small sample size (HFE group: 10 males, 7 females, abduction group: 11 males, 7 females), it is difficult to make any generalizations. Second, the experiment duration was short (only 12 times), and thus further studies are needed to investigate the long-term intervention effects of hip joint exercises using an elastic band. Third, this study did not identify of the effect on strength using an elastic band. In further studies, a comparison of strength with flexion and abduction exercises of the hip joint need to be researched. The findings suggest that hip joint exercises using an elastic band increased dynamic balance, agility and flexibility in healthy subjects. We hope for the conduction of continuous research on the effect of hip joint exercises using an elastic band for improved dynamic balance, agility and flexibility.

\section{Conflict of Interest}

The authors declared no potential conflicts of interest with respect to the authorship and/or publication of this article. 


\section{References}

1. Neumann DA. Kinesiology of the hip: a focus on muscular actions. J Orthop Sports Phys Ther 2010;40:82-94.

2. Horak FB, Henry SM, Shumway-Cook A. Postural perturbations: new insights for treatment of balance disorders. Phys Ther 1997; 77:517-33.

3. Crosbie J, Vachalathiti R, Smith R. Patterns of spinal motion during walking. Gait Posture 1997;5:6-12.

4. Salbach NM, Mayo NE, Wood-Dauphinee S, Hanley JA, Richards CL, Côté R. A task-orientated intervention enhances walking distance and speed in the first year post stroke: a randomized controlled trial. Clin Rehabil 2004;18:509-19.

5. Ferreira GE, Viero CC, Silveira MN, Robinson CC, Silva MF. Immediate effects of hip mobilization on pain and baropodometric variables: a case report. Man Ther 2013;18:628-31.

6. Dolak KL, Silkman C, Medina McKeon J, Hosey RG, Lattermann C, Uhl TL. Hip strengthening prior to functional exercises reduces pain sooner than quadriceps strengthening in females with patellofemoral pain syndrome: a randomized clinical trial. J Orthop Sports Phys Ther 2011;41:560-70.

7. Biscarini A. Determination and optimization of joint torques and joint reaction forces in therapeutic exercises with elastic resistance. Med Eng Phys 2012;34:9-16.

8. Damush TM, Damush JG Jr. The effects of strength training on strength and health-related quality of life in older adult women. Gerontologist 1999;39:705-10.

9. Pages P, Ellenbecker TS. The scientific and clinical application of elastic resistance. Champaign (IL): Human Kinetics; 2003.

10. Park J, Choi W, Lee S. Effect of immediate unilateral whole body vibration on muscle performance and balance in young adults. Phys Ther Rehabil Sci 2013;2:115-8.

11. Eom SY, Lee WJ, Lee JI, Lee EH, Lee HY, Chung EJ. The effect of ankle kinesio taping on range of motion and agility during exercise in university students. Phys Ther Rehabil Sci 2014;3:63-8.

12. Podsiadlo D, Richardson S. The timed "Up and Go": a test of basic functional mobility for frail elderly persons. J Am Geriatr Soc 1991;39:142-8.

13. Chung EJ, Lee B. The effect of treadmill training on dynamic balance and gait function in stroke patient: a pilot randomized controlled trial. Phys Ther Rehabil Sci 2013;2:39-43.

14. Asadi A, Ramírez-Campillo R. Effects of cluster vs. traditional plyometric training sets on maximal-intensity exercise performance. Medicina (Kaunas) 2016;52:41-5.

15. Rao R, Panghate A, Chandanwale A, Sardar I, Ghosh M, Roy M, et al. Clinical comparative study: efficacy and tolerability of tolperisone and thiocolchicoside in acute low back pain and spinal muscle spasticity. Asian Spine J 2012;6:115-22.

16. Santaguida PL, McGill SM. The psoas major muscle: a three-dimensional geometric study. J Biomech 1995;28:339-45.

17. Fredericson M, Cookingham CL, Chaudhari AM, Dowdell BC, Oestreicher N, Sahrmann SA. Hip abductor weakness in distance runners with iliotibial band syndrome. Clin J Sport Med 2000; 10:169-75.

18. Lyons K, Perry J, Gronley JK, Barnes L, Antonelli D. Timing and relative intensity of hip extensor and abductor muscle action during level and stair ambulation. An EMG study. Phys Ther 1983; 63:1597-605.

19. Akuthota V, Nadler SF. Core strengthening. Arch Phys Med Rehabil 2004;85:86-92.

20. Zion AS, De Meersman R, Diamond BE, Bloomfield DM. A home-based resistance-training program using elastic bands for elderly patients with orthostatic hypotension. Clin Auton Res 2003;13:286-92.

21. Kim TW, An DI, Lee HY, Jeong HY, Kim DH, Sung YH. Effects of elastic band exercise on subjects with rounded shoulder posture and forward head posture. J Phys Ther Sci 2016;28:1733-7.

22. Bobath B. Adult hemiplegia: evaluation and treatment. 3rd ed. Oxford, London: Butterworth-Heineman; 1990.

23. Mangione KK, Craik RL, McCormick AA, Blevins HL, White MB, Sullivan-Marx EM, et al. Detectable changes in physical performance measures in elderly African Americans. Phys Ther 2010;90:921-7.

24. Park SY, Kim JK, Lee SA. The effects of a community-centered muscle strengthening exercise program using an elastic band on the physical abilities and quality of life of the rural elderly. J Phys Ther Sci 2015;27:2061-3.

25. Johnson BL, Nelson JK. Practical measurement for evaluation in physical education. 4th ed. Minneapolis: Burgress Pub.; 1996.

26. Delshad M, Ghanbarian A, Mehrabi Y, Sarvghadi F, Ebrahim K. Effect of strength training and short-term detraining on muscle mass in women aged over 50 years old. Int J Prev Med 2013;4: 1386-94. 